\title{
The Collaborative Governance Mechanism and Enlightenment of Singapore Elderly Security System
}

\author{
Yu Juyun, Cai Yucen, Ai Ting \\ Department of Tax and Public Management, Jiangxi University of Finance and Economics, Nanchang, China \\ Email address: \\ 949163985@qq.com (Yu Juyun),86728978@qq.com (Cai Yucen),1792548805@qq.com (Ai Ting)
}

To cite this article:

Yu Juyun, Cai Yucen, Ai Ting. The Collaborative Governance Mechanism and Enlightenment of Singapore Elderly Security System. International Journal of Business and Economics Research. Vol. 7, No. 4, 2018, pp. 88-96. doi: 10.11648/j.ijber.20180704.12

Received: June 14, 2018; Accepted: July 11, 2018; Published: August 6, 2018

\begin{abstract}
The CPF system held by government realize organic combination of housing and pension through purchase allowance and house-for-pension scheme, lifelong income for pension plans guarantees knock-down security. The CPF system has a certain function of redistribution. The government opposes generous welfare system and emphasizes the traditional family values and self-support; through the organic combination of law, principle and emotion, and the employment benefits, the family-support and self-support are unity. Enterprises have the inherent power to hire the elderly. Social organizations in the government's support and control communicate the government and the people with propaganda publicity and providing support for the elderly. The key mechanism of the pension action for multiple unities is the authority government's effective intervention. Its security is the government's strong credibility and public participation mechanism, which is of significance to construct China's old-age security system.
\end{abstract}

Keywords: Singapore, Old Age Security System, Cooperative Governance Mechanism

\section{Introduction}

Singapore's Gini coefficient is relatively high, exceeding the warning line of 0.45 . The polarization is more serious, but the society is very stable. There were as many as 153 strikes in Singapore from July 1961 to September 1962, compared with a total of seven in the next 10 years and almost none today [1]. The social security as a social stabilizer and pressure relief valve must play a huge buffer.

Therefore, it is necessary to analyze Singapore's social security system. The cornerstone of Singapore's social security system is the Central Provident Fund System (CPF), which was established by the government. It was officially implemented in 1955. The original intention of CPF was to maintain social stability and reduce the financial burden of the colonial government. However, after years of development, the scope of use of the central provident fund has been gradually expanded, and the protection project has been developed from the previous single old-age security to Comprehensive security system including retirement protection, medical security, housing security and family security. However, as CPF is a self-protection system of compulsory savings, it is often considered as a self-nursing mode with less mutual aid and weaker redistribution function. It can be seen that relying solely on the government-led CPF system is theoretically difficult to meet the old-age needs of the elderly, and the buffering effect on social contradictions is bound to be limited. Therefore, it is necessary to analyze the contribution of different subjects from the perspectives of government, society, market, family, and individual, as well as the governance mechanism that produces synergies effects.

The following is mainly carried out from four aspects: (1) analyze the relationship between the construction of the elderly security system and the multiple collaborative governance; (2) introduce and analyze Singapore's multiple integrated pension system; (3) explore the formation mechanism of multi-entity collaborative governance; (4) summarize and refine the main points of view, and give some enlightenment to the construction of China's rural old-age security system.

\section{The Construction of the Old-Age Security System and the Pluralistic Cooperative Governance}

In 2000, Singapore entered an aging society. After 2010, the 
elderly population entered a period of rapid growth. In 2011, the proportion of people over 65 years old was $9.3 \%{ }^{1}$. If every woman of child-bearing age had an average of 1.24 children, the proportion of people over 65 years old will reach $36.9 \%$ by 2050 [2]. In order to cope with the aging population, Singapore attaches great importance to the development of the elderly and the construction of the old-age security system.

The current research about Singapore elderly security governance problems are mainly concentrated in the central provident fund system and family-support, and mainly based on the perspective of the government, such as Jia Hongbo and Mu Huaizhong [3] combed and analyzed the development of the central provident fund system in Singapore. Hu Canwei [4] discussed Singapore's successful experience in promoting family pension security through government guidance, legislation and economic assistance. Zhou Suqin and Yang Zhizhen [5] stated the government's various countermeasures to solve the old man's problem. Based on the perspective of the government from security projects including four aspects, such as enhanced hiring, medical care, situ pension and senior citizens culture, Liu Yuling [6] analyzed the successful senior citizens framework, which is limited to the introduction of existing countermeasures. With based on the theory of multi-subject common governance, this paper probes into the formation mechanism of the "multi-body" old-age security system in Singapore and its enlightenment to China.

Old age security system construction belongs to the important content of social governance, which is an important governance mechanism of social risk prevention; because social risks induced root cause is the insufficient supply of public cause of serious inequality and social injustice. In order to resolve social conflicts and promote social stability and harmony, we must strengthen people's livelihood, improve social welfare, and raise the security and happiness of the masses. It can be seen that strengthening the construction of the elderly security system belongs to active social governance, and it needs to be implemented through social governance [7]. Social governance refers to a series of management concepts, methods and means adopted by the government and other social subjects to maintain social stability and realize the maximization of public interests. The core idea is the pluralistic participation, cooperation, the democratization and the institutionalization of social governance and the dynamics of the governance process [8]. From the perspective of the subject, means and goal of social governance, the construction of old age security system is a dynamic process of social governance. In this process, various means should be used in accordance with local conditions by law, principle and emotion that based on the actual situation of national political, economic and social development. At the same time, the government, the market, the family, the social organization, the individual and other pluralistic old-age pension characters will achieve coordinated action on the basis of cooperation. In this way, the integrated old-age security system will be formed, which will guarantee the

1 www.singstat.gov.sg. maintenance of old age.

It is the requirement of welfare pluralism to set up the governance concept of multiple the old-age characters, and it is also a summary of the experience of national old-age security practice. Because the realistic problem of varied and complex completely broke through the public sector governance the scope of self-governance and its limitations, which the importance and necessity of collaborative management of multivariate main body become increasingly prominent, and become the important tendency of government reform. "The hollow country" must become state "The cooperation country" [9]. Collaborative social governance model is based on multilateral consensus to make the decisions [10]. Thus, law, principle and emotion should be combined in terms of governance. "Law" is only internalized as the "principle" of the inner identity of the members of the society so that the people can consciously observe and regulate their own behaviors, so as to achieve the "emotion" governance goal. Otherwise, even strict laws will not protect the pension rights.

\section{Singapore's Elderly Security System Under the Joint Governance of Multiple Subjects}

\subsection{The Government's Pension System}

The government-run pension system, the central provident fund (CPF), was officially implemented in 1955 and is the cornerstone of Singapore's social security system. CPF requires employers and employees to employee salary as the base, in accordance with statutory contribution rates are paid and deposited into employees' provident fund accounts, which is a self security system of compulsory saving and currently covered all employed Singapore citizens and permanent residents. CPF establish original intention is to maintain social stability and reduce the financial burden of the colonial government. CPF did not belong to the social security system at the early stage, but after years of development, it has become a social security system covering housing, pension and medical care.

In order to meet the political commitment to "A householder has his own house", about 80 percent of the public funds (more than 60 percent now) in the 20th century were used to buy houses to repay loans, while very little was made in special accounts aimed at old-age care. Of course, the price of selling flats of the HDB is not only lower than the market price, but also provides home purchase loans and more generous housing purchase allowances. The size of the purchasing flats matches the household income. The lower the family income, the smaller the purchasing flats will be and the higher the government subsidy. In 2015, the price of group houses of a two-room model was 88,000 Singapore dollars before the subsidy, but the actual residents only had to pay 8,000 Singapore dollars, only accounting for $44 \%$ of the annual income of families. Government subsidies reach up to 
80,000 Singapore dollars, which account for 91 percent of the total selling price. But government subsidies for three, four and five homes are much lower as a percentage of the total price and they go down in turn, falling by 38 percent, 18 percent and 8 percent respectively. Moreover, in terms of the absolute subsidy amount, the bigger the group house, the smaller the subsidy, and the government subsidy from 2 to 5 houses is 80,000 Singapore dollars, 70,000 Singapore dollars, 50,000 Singapore dollars and 30,000 Singapore dollars respectively ${ }^{2}$. The ratio of the price of private homes purchased by high-income households or foreigners to the average annual income of households was 10.5 in $2015^{3}$. Visibly, CPF is full of compulsory saving plan, however, because of the subsidy policy of first purchase group housing, so it makes the system have certain income redistribution function and ensures the low-income group house purchasing power. Thus, it embodies the basic principle of social equity and justice and it makes it possible to "a house is cheap and affordable for everyone". At present, more than 90 percent of Singapore's residents own property rights (including flats and houses sold on the market). Singapore houses carry many functions such as social stability, family maintenance, racial harmony, community development and democratic governance [11].

When they are older, they will be set house cash through the "Provide for the aged with house", such as a big house changes a small house, house deed for sale, participation in the elderly red flower scheme or rental housing. They want to ensure that their income after retirement, so that housing and pension can be combined organically. Among them, the repurchase of the house deed is jointly created by the CPF and the Housing Development Board (HDB). The HDB repurchases the deed of houses and issues the dividend. Meanwhile, the CPF will incorporate part of the proceeds from housing sales into the lifetime income scheme to increase pension income for Singapore residents. The organic combination of Singapore's housing and pension systems to ensure a source of income after retirement is conducive to social harmony and stability. As Mr. Lee put it, "the provident fund and home ownership scheme have ensured political stability and sustained Singapore's development for more than 30 years."

To cope with the challenges of longer life expectancy and an ageing population, the central provident fund (CPF) launched "the Provident fund lifetime income scheme", namely CFP life, in September 2009. Since January 2012, under the CFP life plan, the provident fund member who is more than 55 years old can use his retirement savings account (the sum of the balance of common account and special account) to participate in this project. And when he reached the minimum withdrawal age of 65 , he began to extract monthly income that would last a lifetime, that is, too old to draw. Children can also top up their parents' accounts to help them join the provident fund lifelong income scheme, and get

2http://esales.hdb.gov.sg/hdbvsf/eampu05p.nsf/01/15MAYBTO-page-1905/\$file/a bout 0. html

3 Examine the housing market before the budget. Morning post Sunday, Business, March 2, 2016. a corresponding exemption from personal income tax.

Obviously, Singapore's CPF system is a complete social security system, in which housing and old-age care are the main lines. Although CPF implements full personal account accumulation, pension risks are not entirely borne by workers themselves. The government supporting policy of housing purchase allowance and housing endowment combines housing and endowment organically. It not only enhances the resources of endowment, but also makes the fully accumulated personal account have certain redistribution function; through the life-long term income plan, it provides a certain level of life-long security for the elderly. However, the redistributive measures adopted by the government are temporary, rather than welfare guarantees with sufficient and lasting content.

\subsection{The Connection Between Family Pension and Self-Pension}

Singapore attaches great importance to family pension and is the first country to legislate family pension. The law on the Parents maintenance act, which came into force in June 1996, stipulates that children must provide basic needs for Singaporeans aged over 60 who cannot take care of themselves. Of course, legal obligations are not based on the parents' personal habits or expected lifestyle. Here, the judgment standard of "life is not completely self-care" is that all the parents' income and other property are insufficient to meet their basic needs. And support is conditional; if the child can prove that the parents have maltreatment, abandonment and other unfulfilled parenting obligations, or the parents are profligate, the child can be exempt from the responsibility of support. When a maintenance lawsuit is actually settled in court, the court will consider the financial situation, earning power, consumption level, physical and mental health of the plaintiff and the defendant, as well as the defendant's contributions to the plaintiff. In addition, the maintenance obligor shall give priority to the support of his children and spouse over that of his parents.

The law on the Parents maintenance act stipulates the legal obligations of the family to provide for the aged, and at the same time clarifies the responsibility of self-supporting, which makes the concept of self-supporting deeply rooted in the hearts of the people. According to the author's in-depth interview with the elderly ${ }^{4}$, some old people take the initiative to express that they are most opposed to the Chinese idea of "raising children for the aged". They believe that children are under financial pressure and have a heavy burden of raising children, and their children have their own lives. Even if their children have a high income, they should not have more requirements. They believe their children earn more and spend more, such as raising consumption levels, buying cars or

4 During the visit to school in 2016, the author conducted a questionnaire survey on the elderly's pension status, such as their physical condition, financial sources, children's support and work motivation. 200 copies were collected and 191 valid questionnaires were collected, among which 43 old people were interviewed in depth. 
better cars, and getting their grandchildren to accept better education. They think that the idea of waiting, relying and wanting to children should not be allowed. In addition, some old people also take the initiative to reflect that they have not taken good care of their parents, so they are not qualified to ask for their children's meticulous filial piety. That is, the level of filial piety of the elderly themselves is not high, so they have low expectations for their children's pension. Nor, of course, will older Singaporeans, like Chinese parents, use up all their savings or even borrow money to buy a house or conduct a marriage. And unlike western parents who ignore their children completely, they will do their best to help them. It is because the concept of self-care is very strong. As long as the body allows, the elderly in Singapore generally is never too old to do the old.

\subsection{Old-Age Support from Enterprises and Social Organizations}

In addition, employers and social organizations actively participate in and support the elderly care, such as the total number of nursing homes of different natures was 9,755 in 2013, among which, the number of commercial or private nursing homes was 3,270 , accounting for $33.5 \%$ of the total number. Furthermore, the number of nursing homes set up by social organizations such as voluntary/charitable organizations and people's homes/shelters is 5,993 , accounting for $61.5 \%$ of the total number, while the number of government nursing homes is only 1,147 , accounting for $11.8 \%$ of the total number ${ }^{5}$. All illustrates the social organizations actively provide old-age care services. Moreover, many social organizations have various cultural activities for the elderly people, such as Chinese Development Assistance Council (CDAC) creates the silver hair talent program and employment assistance program, etc.

In addition, Singaporean employers have an internal power to hire elder people in self-support by aged. First of all, employers have little to fear from accidents or work-related injuries. Elder people are at significantly higher risk of accidents such as falls and hurt themselves and sudden illness due to a decline in physical function. But employers in Singapore are not worried because the labor department requires employers to buy labor insurance for each worker. In the event of an accident, the cost shall be borne entirely by the insurance. Only in exceptional circumstances can an employer pay a maximum of two months 'salary. And in China, even if the corporation has bought employment injury insurance, the worker still needs to undertake very big responsibility of compensation of industrial injury ${ }^{6}$. Secondly, the public accumulation fund payment rate for the elderly is relatively low. For example, in 2016, employers pay rates (\%) for workers of different ages: $17 \%$ at the age of $35-50,16 \%$ at the age of $50-55,12 \%$ at the age of $55-60,8.5 \%$ at the age of

\footnotetext{
5 Source: lecture notes given by Professor Zhou Sunming from the school of Humanities and Social Sciences (HSS) of Nanyang Technological University (NTU) for the 2016 China university short-term training course. The notes quoted in the following text are directly marked (Zhou Sunming, 2016).

6 Specific content sees "industrial injury insurance byelaw" 29 -39.
}

$60-65$, and $7.5 \%$ above the age of 65 . Finally, the employment system is flexible and there is no minimum wage. Of course, in some low-skilled cleaning and security systems, the wages of migrant workers are also very low, around 800-1200 Singapore dollars. But employers who employ migrant workers, including WP and SP permits, pay 300 to 500 Singapore dollars a month in taxes on migrant workers. (Zhou Sunming, 2016)

\section{The Cooperative Governance Mechanism of "Multi-Body" Old-Age Security System}

According to the above discussion, Singapore's pension governance realized the active participation in multiple subjects. Then, how to form a coordinated endowment action among the various bodies? Its main governance mechanisms include:

\subsection{Authoritarian Politics and Public Participation}

After Singapore became one of the Asian Four Tigers in the 1970s, it is not like other Asian developed countries or regions such as Japan, South Korea, Taiwan, China adopts a more generous pension security system, but continues to adhere to mandatory savings of the central provident fund system, and strengthen the function of the system. Because the People's Action Party opposes the generous welfare policies of the west, and advocates that the people must work without relief. The government helped them in their shortcomings. The welfare of Singapore is mainly employment benefit: There are benefits to work; No job, no benefits. The guiding ideology of concept of welfare is Trickle-down Economics, which argues that the best way to help the poor is not relief but development. Through the Trickle-down Effect Theory benefit them: namely priority groups for development or regions benefit them through consumption, employment, etc. and promote their development and prosperity, rather than giving special privileges to the poor class or region.

The ruling ideas and values of the People's Action Party can be carried out through policies, which can be understood and supported by the people and implemented in practice. As described above, it is one of the evidence that Singapore's old man universally work and the strongly concept of Self pension. The main reason is that people believe honesty and high efficiency People's Action Party government, especially the founding generation who cherish the good life today extraordinary undergo the race riots. And people respect and even worship Lee kuan yew, so trust his administration very much. The trust of the people, of course, mainly from the authority government's credibility rather than the imperial power in ancient China, which based on the official and people closely related, Democratic cooperation and fully understand the pension policy by public. Singapore's MediShield Life, for example, will be heavily advertised through the media and social organizations before it is officially implemented, and will hold a number of speeches 
and question-and-answer meeting for the public. The Singaporean government is good at listening to public opinion, such as the annual budget is conducted an opinion poll before and after congressional approval in Singapore.

Because the interaction mechanism between Singapore government and social is perfect, there is not only a large number of social organizations that serve as intermediate bridges, but also a platform for direct dialogue between the officials and people. With the strong support and development of the government, Singapore has formed a large number of social organizations with extensive coverage. The government makes full use of social organization to promote the political party, to collect public opinion, to better develop and implement policy. It not only closes relations between the officers and people, and fully mobilizes the enthusiasm of the social public participation, but also has formed a good mechanism for the co-governance of multiple subjects. Some attitudes of the old man of the underclass working are very good and they said:" Rich people have their rich lifestyles; the poor have the advantage of the poor. So do not need to compare with the others". It should not leave various publicity and communication of the social organizations and positive transfer the healthy life idea, such as community organizations will make the interpretation of the "towards the path to happiness "and send materials. Through community organizations, the government closely connects residents and families, and has an invisible supervision effect on family pension.

"Singapore-style democracy" has effectively implemented the principle of mass democracy and truly served the people. The direct communication channels between the government and the people are very smooth [12]. There are 89 members of congress in 89 districts in Singapore, and each district is arranged for the councilors' reception days once a week. For example, Nan Yang community ${ }^{7}$ every Monday night at 8 -$10 \mathrm{PM}$ is the councilors' reception time, where the number of visitors per week is about thirty. The reception residents can reflect any demands and can be received attention. If the elderly people with children are abandoned, the relevant government officials will talk with their children and adjust or deal with the family maintenance problems in time. Of course, government officials and even Prime Minister Lee Hsien Loong have their own web pages, which can interact directly with the public. Singaporeans often say: "Our policies are always changing, as long as people say it is bad so government will change. It shows that the social governance in Singapore is very flexible, and the interaction between the officials and the people is good, meanwhile, it reflects the high trust of the public in the government.

\subsection{Active and Effective Government Policy Interventions}

The People's Action Party (PAP) put forward common values in 1991: The state supreme, the society first; Family is the root and society is the foundation.... In front of the supreme national interest, the PAP's authoritarian politics has a legitimate ideology. The party and the state are united, and

7 The community is the author lived during the visit to NTU in 2016. the PAP equals the government and the state. The government led by the PAP is highly effective, honest, authoritative and highly interventionist. The government should not only defend national sovereignty, vigorously develop the economy, control the election and political parties, but also control and guide the speech and behavior of the national. The state is the enlargement of the home and the leader of the country is the head of a large family. The control of state power goes deep into all aspects of society, individuals and families [13].

Aside from enforcing the system of CPF, government also has a series of measures that help seniors enjoy their old age in peace: Launched in 2014 the government form a complete set of $\mathrm{S} \$ 8$ billion aid package, the pioneer generation ${ }^{8}$ join the more generous lifelong health insurance scheme (like the Medishield Life) at a lower premium than current the rates (like the MediShield) ${ }^{9}$. In 2015, the financial budget proposed that earners who are the elderly and low income would receive a lifetime subsidy of 600 Singapore dollars per person and per quarter. People aged 56 to 64 are entitled to an S\$300 extra Goods and Services Tax (GST) Voucher with Seniors' Bonus, and additional S\$600 can be obtained from over 65 years old; over the age of over 55 will receive a $1 \%$ extra interest rate for the first $\$ \$ 30,000$ in a CPF account ${ }^{10}$. The People's Action Party opposes generous welfare, but the government will not leave the poor without food. Lee hsien loong in 2012 pointed out that the low income family members obtain the government subsidies in life, including housing allowances, education grants, medicaid, employment income subsidies and water and electricity rebates, etc. It is expected to exceed S\$500,000 (Zhou Sunming, 2016)

Furthermore, the government has issued a number of operable preferential policies, which actively give play to the pension function of multiple subjects and form a synergistic pension effect.

\subsubsection{Support the Development of Social Organizations}

In order to promote the development of social enterprises, the government of Singapore has provided convenience and support in public policy, capital, human resource reserve, cultural identity and capacity building. Singapore is a typical example of the rapid development of social enterprises through macro policies [14]. Among them, the most powerful form of supporting is the provision of funds, such as the government allocates administrative expenses to charities through the national welfare council, which accounts for about $50 \%$ of the administrative costs of charitable organizations [15]. At the same time, The government makes different kinds of laws depending on the different nature of the organization, such as for laws against non-specific social organizations, there are the "Association Law", the "Charity Law", the "Corporation Law" and the "Cooperative law", etc.;

8 The "pioneer generation" refers to the first generation of Singaporeans born before 1950, who became citizens before 1987, and who lived or worked locally. 9 By the end of 2015, Singapore will have fully transitioned from its existing MediShield to MediShield Life. It's a mandatory, universal, lifelong insurance plan. 10 It is notes given by Dai Shiyan, deputy dean of NTU Nanyang Graduate school of Public Administration (NCPA), for the 2016 China university short-term training course. 
for the law of a specific social organization has the "National Welfare Council Act", the "People's Association Act" and the "Income Tax Law" and other relevant provisions of the law. Thus, the management and supervision of social organizations should be realized and active intervention should be taken. The government's control over social organizations is also reflected in the subordination relationship. Most of Singapore's core social organizations are under the jurisdiction of specific government departments. Even private organizations are essentially subject to official organizations. As the National Welfare Council and the People's Association are affiliated to the ministry of social development, youth and sports, and the chairman of the Welfare Council is appointed by the minister.

\subsubsection{Strengthen Family Support}

Although legal family support cannot meet the needs of the elderly, the Singapore government has introduced a series of incentives to strengthen family support. Linking care for the elderly to the purchase or rental of flats, such as priority is given to the family of three generations to buy the group house and give preferential price; Tax deductions for taxpayers who live with elderly parents and pay for their grandparents' retirement accounts of provident fund... These measures are designed to encourage families to strengthen the life care and spiritual comfort for the elderly [16].

\subsubsection{Multi-directional Support for Individual Pension}

The law of Parents Maintenance stipulates the legal obligations of the family to provide for the aged while clarifying the responsibility of self-supporting, and supports the employment of the aged in various aspects, so as to increase the resources for self-supporting. The main measures are: First, promoting the establishment of senior employment organizations. To expand employment opportunities for the elderly, the Singapore government has set up several committees and organizations for the employment of the elderly to study. Second, the government will improve relevant laws and regulations. In terms of increasing employment, the government introduced the Retirement and Reemployment act in 2012. In addition, in order to ensure the employment opportunities of Singaporeans, the government sets a minimum percentage of Singaporeans employed by companies. If the minimum proportion is not reached, the employer is not qualified to apply for foreign labors. In addition to the work that Singaporeans do not want to do, the average employer is required three Singaporeans to apply for a foreign worker. At the same time, the company is funded to carry out comprehensive job redesign and wage system reforms which provide more employment opportunities for older workers. Third, government carries out employment subsidies and employment publicity for elderly. As from April 11, 2016, the Labor Bureau has published a series of "senior workers" advertisements in four languages in the major newspapers for six weeks, costing $\$ \$ 400,000^{11}$.

11 "70-Age action plans to build a friendly elderly society", Union Morning Paper, February 25, 2016

\subsection{Organic Combination of Law, Principle and Emotion}

The old-age pension that can best reflect the organic combination of law, principle and emotion is the informal family pension. The Law on Parents Maintenance stipulates the family's statutory duty of maintenance and is considered to be the practice of honoring parents' thoughts of the Confucian tradition. What about the facts? Focusing on the traditional filial piety expressed in the "The Classic of Filial Piety" of the Confucian ethics, "Indeed, family reverence is the constancy of the heavenly cycles, the appropriate responsiveness of the earth, and the proper conduct of the people." According to the life process of the father, such as birth, oldness, illness and death, the specific requirements of "filial piety" are put forward:" Filial children are respectful to their parents in daily life, make the parents happy when they are old and worry about the parents when they are sick. The filial children should have the mournful state of filial piety when parents die and sacrifice according to the rules of etiquette."; "A man's conduct is not greater than his filial piety". Filial piety is the origin of all virtues, and is the source of human education. The Confucian standard of traditional filial piety: filial piety towards parents is natural and unconditional; and the content of filial piety is all-encompassing from the spirit to the material, that is, the child is required to undertake infinite absolute parental obligations to the parents. However, the Parents Maintenance Act only stipulates that children provide the lowest level of pension support for parents over 60 years old who cannot support themselves, and emphasizes the consistency of rights and duties, and the care of their own children and family takes precedence over the care of their parents. (For details, see the above discussion)....... Obviously, the statutory maintenance responsibilities of Singaporean families are different from traditional Chinese standards of the Confucian filial piety. It reflects the core values of Singapore's comprehensive culture. Because from the process of cultural integration to the development of comprehensive culture, although Singapore in different stage in view of the practical problems take different cultural strategies, but it's hard to find the Confucian culture plays a consistent leading role. [17] It is in line with the modern spirit of the rule of law and the principles recognized by Singapore's civil society, realizing the mutual integration of law and principles, and effectively ensuring the implementation of the legal responsibility of family maintenance.

Although the law stipulates that the responsibility for family pension cannot meet the elderly's need for old-age care, the government encourages families to support old-age care in various ways and vigorously promotes the filial piety culture. Singaporeans believes that "loyalty, filial piety, benevolence, courtesy, integrity and shame" is the core of Confucianism, the code of conduct of people, and the "principle of governance" of the government, in which "Filial piety" refers to respect and filial piety their elders. Lee Kuan Yew has repeatedly emphasized that the family is an absolutely important basic social unit from the home to the extended family, to the family, 
and to the country [18]. In 1994, Goh Chok Tong emphasized at the celebration of the National Day that traditional family values are the "value cornerstones". We must hold high these values and stabilize families and countries. If the filial piety is not taken seriously, the embodiment of existence will become weak, and the civilized way of life will become rough [19]: p201. Policies should ensure the rights, interests and privileges of parents in order to regulate the responsibilities and duties of family members. In the 2008 New Year message, Prime Minister Lee Hsien Loong stated that the government assists low-income workers through the employment award scheme, but we must not undermine the traditional duties of the family, especially taking care of the elderly [20].

The government not only regards "filial piety" as a rule of governance, but also stipulated that the family should provide old-age support through law. Moreover, the PAP leaders have repeatedly emphasized the concept of Singapore's traditional family on important occasions and conducted regular media campaigns through the media and social organizations. It is true that "the action of the law" is accompanied by "To understand reason, to touch heart". However, encouraging family pensions does not mean ignoring the responsibility for self-care. Because the People's Action Party does not advocate for the relief of the people, the people must work, and the elderly are no exception. They also support the employment of the elderly through various means and increase the resources for the elderly. Of course, actively promoting the employment of the elderly is also one of the measures to make up for the labor shortage and promote economic development. For example, in the population structure in 2010 , citizens accounted for $63.6 \%$, permanent residents accounted for $10.7 \%$, and foreign workers had increased from $2.9 \%$ in 1970 to $25.7 \%$ [21].

It can be seen that the government of Singapore has unimpeded communication with families and the public, and there are incentive measures to strengthen family pension and guarantee self-pension. The concept of self-care has been deeply rooted in the people's mind, and the multi-subject pension action is synergistic [22].

\section{Conclusions and Inspiration}

\subsection{The Main Conclusion}

The Central Provident Fund system is a formal pension system. It mainly relies on the authority politics of the government to persist and develop. Meanwhile, it collects public opinions and improves policies through a good interaction mechanism between officials and people. Through the support policy of the house purchase allowance and the housing endowment, this policy combines housing and endowment organically, providing a certain level of lifelong security for the aged through the lifelong income plan. However, the level of security provided by CPF is not sufficient, and it requires families, society, individuals and the market to participate in the endowment supply.

Singapore has developed a multi-pronged pension system.
Among them, the CPF is a kind of formal pension security system; self endowment is an important power; family endowment has to ensure the basic survival of the old legal obligation; enterprise and society is an indispensable auxiliary power. In many subjects, the government is the core, social organizations are the bridge, families are the foundation, the market is the supplement and self-supporting is positive.

The key mechanism of synergistic effect between multiple subjects is the efficient intervention of authoritative government, whose main means is the organic combination of "law, principle, sentiment and benefit". Main measures: firstly, the legal obligation of providing for the aged through the Maintenance of Parents Act is to guarantee the basic survival of the aged. On important occasions, leaders of the People's Action Party have repeatedly stressed Singapore's traditional family concept, promoted Confucian filial piety culture and strengthened the traditional family pension function. Secondly, we will encourage children to support the elderly through preferential tax policies, housing subsidies and other economic means. Thirdly, through the system design and interest incentives, enterprises are encouraged to provide jobs for the elderly to ensure self-supporting. For example, the enterprise pays low public accumulation fund for the elderly, and the enterprise can obtain such policies as post subsidy for the elderly, so that the enterprise has the intrinsic motivation to hire the elderly. Lastly, we will support the development of social organizations through policy support, especially the fund supply policy, so as to give play to the role of social organizations as a bridge between different pension entities. Pension play to social organization at the same time, the majority of social organization is not only aiming at the elderly carry out various cultural activities and employment assistance plan, but setting up nursing home account for most of Singapore.

Singapore's social endowment governance has achieved democratic cooperation and multi-participation on the basis of laws and institutions. At the same time, it emphasized the central leading role of the government and formed a "One core and pluralism" collaborative governance model. In the construction of the entire old-age security system, it has always emphasized the core leading functions of the government. Through strong government intervention, the government's pension concept and intervention measures are coordinated with Singapore's culture, family form, and national supreme values. It has formed its own unique and constantly developing pension security model.

\subsection{Lessons for China}

The Singapore government and political elite abandon the universal principle and form their own unique and continuously changing governance concepts and models [23]. Old-age security governance is no exception. The Singapore's concept of "One core and pluralism" coordinated pension management is of great significance to the construction of China's rural old-age security system. In the process of the social governance of the rural old-age security system, the Chinese government should provide service and guidance 
with "Not tired of it". Through the change of government function, it can better mobilize the family, society and other forces to participate in a wide range of pension provision, and prompt supply behavior to achieve synergies between multiple subjects, in order to better meet the demand of the rural elderly pension service. First of all, we must set up the modern concept of social governance, from the height of the top-level design, such as by modifying the protection of old people's rights, to reasonably position the family pension responsibility and supplement the neglect of self-consciousness. Then, we should establish the status of self-supporting subject and enhance the operability of law. We should advocate the concept of self-care, rebuild harmonious intergenerational relations between families and reduce the intergenerational exploitation of the elderly.

But collaborative governance also has the dilemma of ability, action, responsibility and value [24]. There are huge differences in the politics, economy, culture, and labor force structures between China and Singapore. For example, Singapore's service industry accounts for more than $70 \%$ of the total industry, and the labor demand gap is relatively large. Jobs suitable for the elderly are more. The government has the motivation and ability to encourage the elderly to get full employment and support self-care, but China does not have the reality of providing full employment for the elderly. Therefore, we must pay attention to the strength and methods of self-care promotion. Otherwise, it will neither strengthen self-supporting pensions, but may further weaken the family pension. Once family values are lost, it is difficult to retrieve them. China needs to protect and promote the rational core of Confucian filial piety culture, such as Singapore's law on the Parents maintenance act stipulates "The maintenance obligor shall give priority to the support of his children and spouse over that of his parents" is not desirable. The construction of China's old-age security system must reflect the core values of socialism.

In addition, with the economic growth, the CPF system has become increasingly unfair, and it requires individuals and families to bear unreasonable old-age risks. This artificial institutional arrangement reflects the social Darwinian ideology of "survival of the fittest, superior win and the inferior wash out" and the need for social and political control [25]. This kind of welfare concept does not conform to the principle of social fairness and justice, because the right to old-age care is a right of existence and an important part of human rights. Old people must not only "superior win" but also "inferior survival". The International Labor Organization held its 101st session in Geneva in 2012 and put forward the "Proposal on the bottom line of national social protection" (Proposal No. 202), which has won the support and response of many countries in the world. The concept of social protection bottom line does not refer to temporary and crisis-based social assistance. Instead, it creates a welfare guarantee with sufficient and lasting content under an inclusive development strategy, such as ensuring that everyone is eligible for a basic annuity for old age or disability; It is pointed out that expanding social welfare contributes to economic development and avoiding social tension and division. Social inclusion is now a national priority and Singapore policy needs to be repositioned in a wide range of areas in the future [26].

\section{Fund Project}

"An empirical study on the impact of new agricultural insurance on the quality of life of the elderly population" under The National Social Science Fund of China (14BSH113).

\section{References}

[1] Lee Kuan Yew. Memoirs of Lee Kuan Yew (1965-2000) [M]. Hong Kong: Federal Press (New) Pte Ltd, 2000.

[2] Yap, M., Gee, C. Population Outcomes: Singapore 2050 [M]. Singapore: Institute of Policy Studies, 2014.

[3] Jia Hongbo, Mu Huaizhong. Analysis on the Reform of Singapore's Central Provident Fund System [J]. Journal of Beijing Jiaotong University (Social Science Edition), 2009, (4):92-95.

[4] Hu Canwei. The Family Pension Model of Singapore and its Enlightenment [J]. Journal of Yunnan University of Nationalities, 2003, (3):35-38.

[5] Zhou Suqin, Yang Zhizhen. A Brief Analysis of Singapore's Elderly Problem and the Government's Countermeasures [J]. Southeast Asia, 2002(11):44-47.

[6] Liu Yulling. Singapore Observation: the Four-in-one Successful Aging Framework [J]. Special Zone Economy, 2014(5):134-135.

[7] Jiang Xiaoping. Social Governance System Innovation in the Modernization of National Governance [J]. China Administration, 2014, (2):24-28.

[8] Zhou Xiaoli, Dang Xiuyun. Social Governance in Western Countries: Mechanisms, Concepts and Implications [J]. Nanjing Social Science, 2013(10):75-81.

[9] Robert, A. Managing Collaborative Public Performance [J]. Public and Management Review, 2005, 29.

[10] Ansell, C., Alison Gash, A. Collaborative Governance in Theory and Practice [J]. Journal of Public Administration Research and Theory. 2007,18.

[11] Xu Guochong. Political Implications of “HDB" : Inspiration from Singapore's Housing Policy [J], China Administration, 2017(3):145-150.

[12] Sun Jingfeng, Liu Jiabao. New Theory of "Singapore-style democracy" [J], Journal of social science in Jilin university, 2016(5):73-82.

[13] Fan Ruolan. An Analysis on the Relationship between Women's Rights and Patriarchy in Singapore [J]. Southeast Asian Studies, 2016(1):4-10.

[14] LI Jian: How can the government promote the development of social enterprises? --Experiences from Singapore [J], Economic restructuring, 2016(5):19-24. 
[15] He Xiaopei. Singapore Social Organization Survey [J]. Group Article in Heaven and Earth, 2011(16):263-264.

[16] Xu Zhenghua, Hu Ganyong. Commentary on the Law on the Maintenance of Parents in Singapore and its Implications for China [J]. Jiangxi Social Science, 2012(9):151-155.

[17] Chen Zuzhou. From Multiculturalism to Comprehensive Culture: on the Relationship between Confucian Culture and Singapore's Economic Modernization [J]. Journal of Nanjing University, 2004(6):134-141.

[18] Lee Kuan Yew. Changes in Singapore - Premier Li Delivers a Speech to Nus and Nanyang Technological Students [N]. United Morning Post, 1988-8-30.

[19] Wu Yuanhua. Good Governance in Singapore [M]. Beijing: China Social Science Press, 2012:161, 201, 176.

[20] Goh Chok Tong, G. C. Moral Values: The Foundation of a Vibrant State [J]. National Day Rally Address, 21 August 1994,21(8).
[21] Saw, S. H. The Population of Singapore (3rd edn)[M]. Singapore: Institute of South East Asian Studies, 2012.

[22] Yu Juyun. A Comparative Study on "Maintenance of Parents Act" between China and Singapore-- Based on Multiple Coordinate Governance Mechanism [J]. Foreign Social Science, 2017.3:136-144.

[23] Yu Wenxuan. The law is Capricious -- Singapore's Public Administration [M]. Shanghai Sanlian Bookstore, 2015:6.

[24] Yu Juyun. The Replacement Rate and Equity Evaluation of Endowment Insurance System before and after Merger [J]. Reform, 2015 (7):82-90.

[25] Mukul, G. A., Nandy, A Singapore's Policy Responses to Aging, Inequality and Poverty: An Assessment [J]. International Social Security Review, 2008.1

[26] Irene, Y. H. Being Poor in a Rich 'Nanny State': Developments in Singapore Social Welfare [J]. The Singapore Economic Review, 2015, 3. 